\title{
Outreach in optics for developing countries: International School of Photonics model
}

Jemy James, Praveen Ashok, Jijo P. U., V. P. Nampoori

Jemy James, Praveen Cheriyan Ashok, Jijo P. U., V. P. N. Nampoori, "Outreach in optics for developing countries: International School of Photonics model," Proc. SPIE 9666, 11th Education and Training in Optics and

Photonics Conference, 96660G (5 June 2009); doi: 10.1117/12.2207943

SPIE Event: Eleventh International Topical Meeting on Education and Training in Optics and Photonics, 2009, St. Asaph, United Kingdom 


\title{
Outreach in Optics for Developing Countries - International School of Photonics Model
}

\author{
Jemy James ${ }^{1}$, Praveen Cheriyan Ashok ${ }^{\star 1,2}$, Jijo P.U. ${ }^{1}$, V. P. N. Nampoori ${ }^{1}$ \\ ${ }^{1}$ Cochin University of Science and Technology, Cochin, India \\ ${ }^{2}$ Univrersity of St. Andrews, Fife, UK \\ *Email: praveencashok@gmail.com
}

\section{ABSTRACT}

The education system of developing countries like India lack infrastructure for teaching science through demonstrations and experiments. The teaching of optics is generally based on factual data given in text books. Students are forced to believe natural phenomena without actually getting convinced themselves through observations. This imparts a big flaw in the way students understand and experience science. The International School of Photonics SPIE (International Society for Optical Engineering) Student chapter, in Cochin University of Science and Technology (CUSAT) in India comes up with their outreach activities, which is mainly aimed at giving hands on experience for school students with Optics. The pedagogy is completely in tune with the syllabus of Indian schools. This activity is being conducted by the students who are studying Photonics in University level. This gives the students a teaching experience as well. The outreach activity has been designed in two modes - Optics Fair \& Optics to School.

Optics Fair is a massive outreach program which has being conducted yearly since 2006 . The two day event attracts more than 1500 school students as well as general public every year. The event is divided into three sections;-Primary, Secondary \& Higher Secondary and the experiments are carefully chosen that the students will be able to appreciate them with their prior knowledge in optics. The basic idea put forward is "See and Believe". In three years this event has become very popular attracting more and more students each year.

Optics to School is another mode of the outreach activity where the volunteers go to schools for a one day session where optics experiments are demonstrated to students in interesting and exciting way. The idea is to reach students in the schools in rural areas who are not able to take part in the Optics Fair due to economic constraints for transportation. This activity also has been running for past 3 years successfully.

The response received for these outreach activities is overwhelming. Program is successful in its mission to invoke curiosity and interest in students towards optics. Also within the given time constraint the program is able to give an insight of subject to students.

\section{KEY WORDS}

Optics Education, Optics outreach, Hand on Optics 


\section{INTRODUCTION}

Developing countries faces fundamental limitation in developing an effective pedagogy in science at school level. The main reasons for this limitation are the lack of facility and lack of training for science teachers ${ }^{[1]}$. Even though the science education syllabus covers broad area of science, students remain ignorant about the new technological development in various fields of science as the syllabus is not getting revised duly. Motivating students at school level will result in the development of the field of science which in turn will help in the development of the economy of a country ${ }^{[2]}$.

Last two decades witnessed tremendous growth in the field of Optical and Photonics and its application to various fields like communication, healthcare, environmental studies, astronomy, energy harvesting etc. In India, the physics syllabus in schools follows traditional contents. The traditional content does not emphasize the import of optics in today's technology arena. This makes it essential to run a campaign in order to introduce the beauty of the field of optics to school students and making them aware of the state of the art in various technologies involving optics, with an objective to invoke interest in students towards optics.

The ultimate solution to this problem lies in improving the overall quality of education. It should involve due revision of syllabus to include contemporary development in the subject and giving proper training for the teachers. An important factor to improve the quality of science education is to improve the laboratory facilities in schools. It requires huge investment in order to achieve all above stated goals. Hence these goals are achievable only in a long term basis.

A quick and partial solution is to seek a parallel approach where universities and research institution use their human resource to communicate the new development happening in science to school students through outreach activities. This is the reason why various organizations like International Society of Optical Engineers (SPIE) ${ }^{[3]}$, Optical Society of America (OSA), United Nations Educational, Scientific and Cultural Organization (UNESCO $)^{[4]}$ encourages optics outreach activities in developing countries.

International School of Photonics SPIE (ISP-SPIE) student chapter in collaboration with OSA student chapter designed its outreach programs in order to bring the message of light to school students.

\section{BACKGROUND}

ISP-SPIE student chapter and ISP - OSA student chapter involve a group of students consists of undergraduate, postgraduate and research students whose main focal area of study is Photonics. From first year onwards the chapter was keen in spreading the message of light through outreach activities. The outreach programs were developed in order to give students hands on experience with some basic optics experiments. The activities were mainly of two types. One in which volunteers go to school and carryout a one day long session involving presentation, hands on experiments. Second approach was to conduct a massive outreach program ("Optics Fair") which was designed in an exhibition mode catering a large group of students in a short span of time.

The main financial backing required for these activities came from SPIE and OSA. Also we could attract local sponsorship in order to meet the financial requirements.

\section{DESIGN OF CONTENT}

The main design consideration of the activity was to give participants maximum knowledge in the limited time available. The learning environment should be different from usual classroom environment in order to ensure that students get maximum out of such programs. Learning through activity was the solution 
we found for this challenge. Activity based teaching is a very effective mode of teaching and it ensures that student will find learning experience interesting.

The content to be included for each session varies depending on the target audience. The content of the program was designed depending on the level of knowledge in optics for the target audience. Based on this concept we categorized the target audience who are school students into three categories.

The first category included students till $7^{\text {th }}$ standard ${ }^{1}$. The knowledge level in optics for this category of students is very low. Optics is not introduced as a subject into their curriculum at this level. The students would have naïve ideas about phenomena like reflection, refraction etc., about which they have not studies systematically at this level. The aim of package we created for this level of students is to "fascinate" them with light and colors. To give them a visual experience of light. There were three separately designed sessions based on different themes. A session on "colors" was designed aiming at Lower Primary students. This session included activities to teach students basic concepts of colors like primary colors, mixing of colors etc. Also there were some interesting optical illusions in order to make the session more interesting. The theme for another session was "Reflection". This session included activities like building Kaleidoscope, periscope etc. aimed to give a feel about the phenomena of reflection to students. The third session was based on "Refraction" where activities which demonstrate phenomena based on refraction were included.

The second category included students in high school. At this stage students were introduced to the field of optics in a systematic way. They would have studied ray optics and phenomena like reflection refraction etc. They would have studied action of spherical mirrors and lenses based on ray optics model and also would have introduced to some basic optical instruments like microscope, telescope etc. Even though the students had studied about basic ray optics and about basic optical instruments, they would not have used an optical instrument or seen what they have studied in action. The tagline for the package for this category of students is "believe through experiment". The package involved simple optical experiments which can be explained using ray optics. It also included some demonstrations which can invoke inquisitiveness in students to explore more about the field of optics.

The third category consisted of students in higher secondary level. This is the stage when students are introduced to concept of wave optics. At this stage students might be doing some ray optics based experiments. But normally there would not be any wave optics based experiment included in the curriculum. Students are forced to learn phenomena like interference, diffraction, polarization etc. without seeing actual experiment. In contrast to the ray optics concept which is quite intuitive, concept of wave optics is hard to digest for a prejudiced mind which understands ray optics in terms of Newton's corpuscular theory. This creates aversion in students towards the subject of optics when they are introduced to wave optics. The package designed in this category aims at demonstrating classical experiments which led to the advent of the field of wave optics. Classic wave optics experiments like Young's double slit experiments, single slit diffraction etc. are difficult to realize using a white light source. This was the reason why these experiments were not accessible for school students. Today the availability of cheap diode laser pointers opened up new opportunity to setup such experiments easily.

Each session was designed to be for one hour for a group of 30 to 40 students. The sessions mainly involved activity. The activities did not involve any quantitative measurements. Rather students were expected to experience various phenomena qualitatively which would supplement their text book based knowledge. The design concept for the content is summarized in figure 1.

${ }^{1}$ In Indian educational system, school education is for 12 years. $8^{\text {th }}$ standard to $10^{\text {th }}$ standard is referred as High school and $11^{\text {th }}$ and $12^{\text {th }}$ standard are referred as Higher secondary 


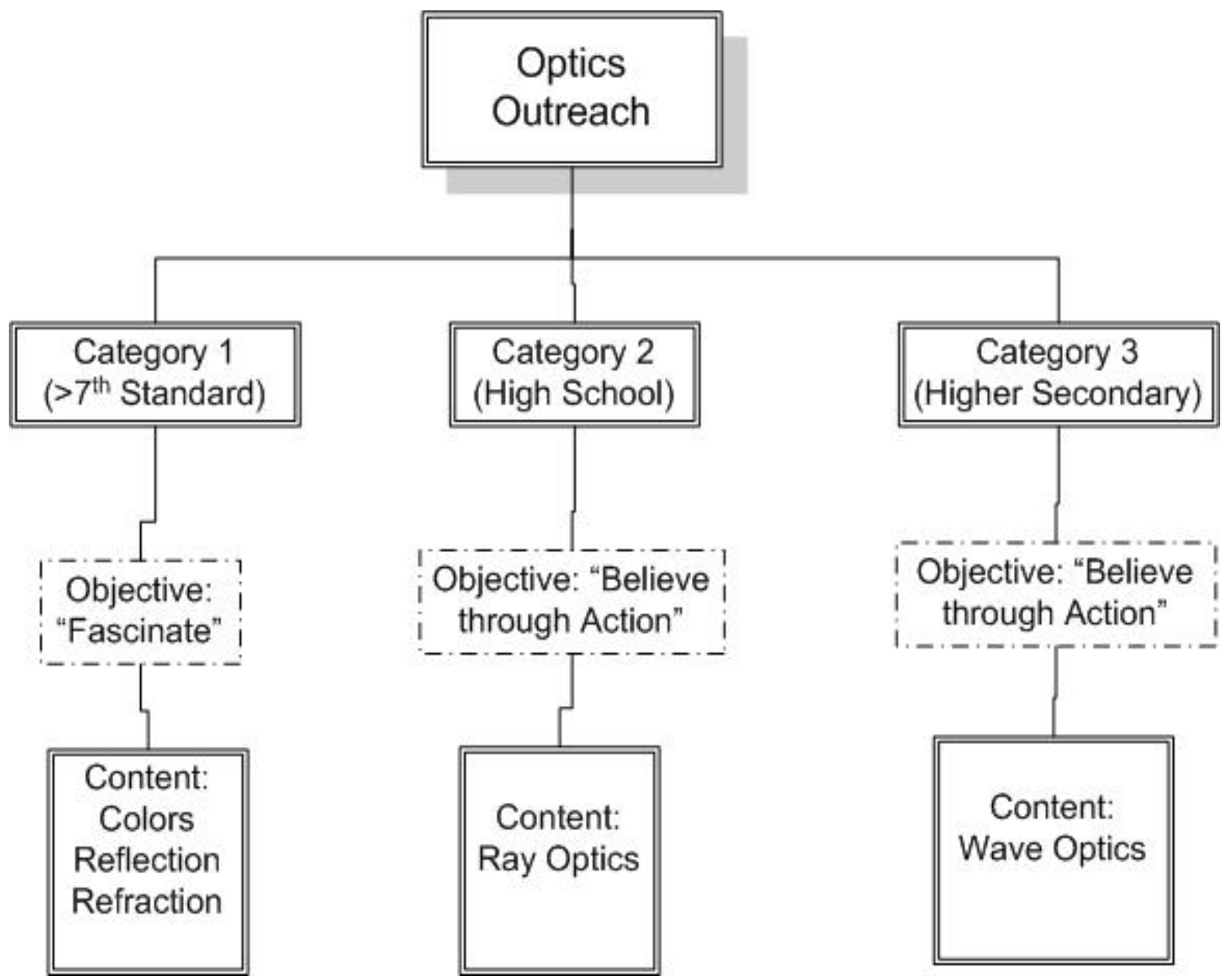

Figure 1: Design considerations

Other than the main focal theme, activities and experiments that introduce students to the field of lasers and optical fibers were included in sessions of category 2 and 3 . This helps to make students understand the important role Optics and Photonics play in our day today life. It would in turn invoke interest in students in order to learn about the development happening in the field of Optics and Photonics.

\section{Experiments}

This section gives complete list of experiments setup for various sections. The experiments involved in this instructional package are standard optics experiments. But the presentation method and the objective of including specific experiment in specific category added value to the whole package. 
The main experiments and activities included in category 1 is given below.

- Colors

o Newton's color disc

o Primary colors

o Rainbow creation

o Optical illusions

- Reflection

o Mirror

o Kaleidoscope

- Refraction

o Bending of light and illusions associated with it

o Lens

o Telescope

The category 2 which mainly focused on ray optics based demonstration included experiments listed below.

- Telescope

- $\quad$ Microscope

- Prism and dispersion

- Total internal reflection

- Scattering of light

- Eye

- Light and lasers

- Tyndall experiment for wave guiding

The list of experiments included in category 3 is given below.

- Interference - Young's double slit experiment

- Diffraction

o Single slit diffraction

o Diffraction grating 
- Polarization

o Polarizer and analyzer

o Photoelasticity

- Lasers and its applications

- Optical fibers

- Optical fiber communication

- Holography

\section{OPTICS TO SCHOOL}

This program is designed to run as a whole day program in a school. A group involving 20 to 30 volunteers would go to the school and setup the experiments mentioned in the previous section, depending on the target audience. The program starts with a presentation in order to introduce the students to the objective of this program. Also students would be shows presentation of various fascinating development happening in the field of optics and Photonics at present.

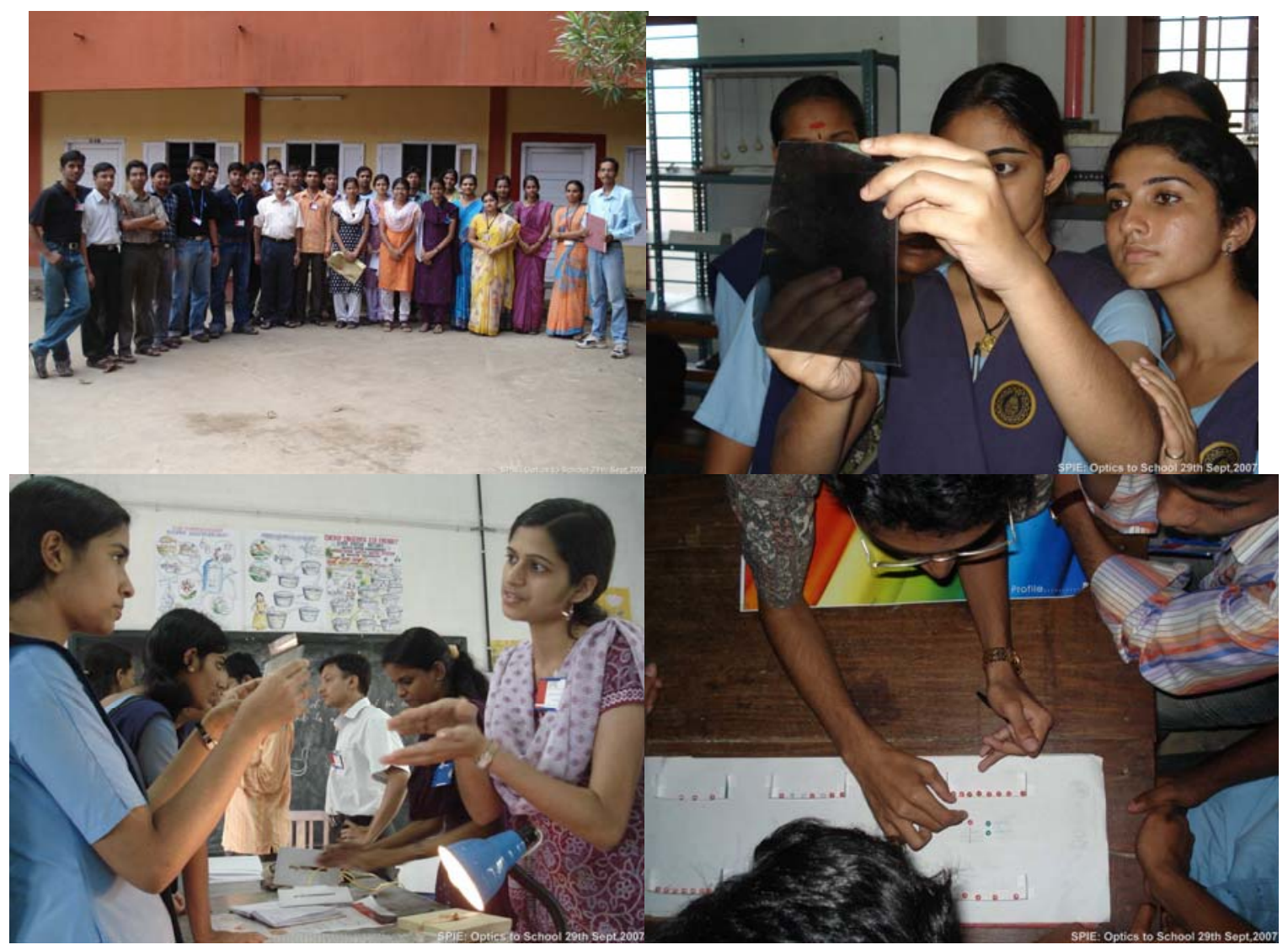

Figure 2: Photos of Optics to School program 
This session would be followed by activity session where one or two volunteers would be assigned to a particular experiment. A group of four to seven students will spend 15 minutes on a particular experiment. They would get opportunity to get hands on experience with each demonstration and the volunteers would be explaining the experiment to students. Thus in a single session which last one to one and a half hour, students would be going through four to five experiments and they would be given enough time to clarify the doubts arising while going through these activities.

The presentation mode was kept deliberately informal in order for students to give a completely stress free learning experience. This helped in invoking inquisitiveness in students.

The program gained very enthusiastic and positive response for past four years. Students showed enthusiasm to get involved in the activities included in the demonstration session and they actively participated in the discussions. Students came up with interesting doubt which is the proof that the program was successful in invoking the inquisitiveness in students. The feedback obtained from teachers was also overwhelming. They considered this program as a way to sharpen their knowledge. Also this activity based instructional package acted as a supplement to the standard textbook which made further teaching easier.

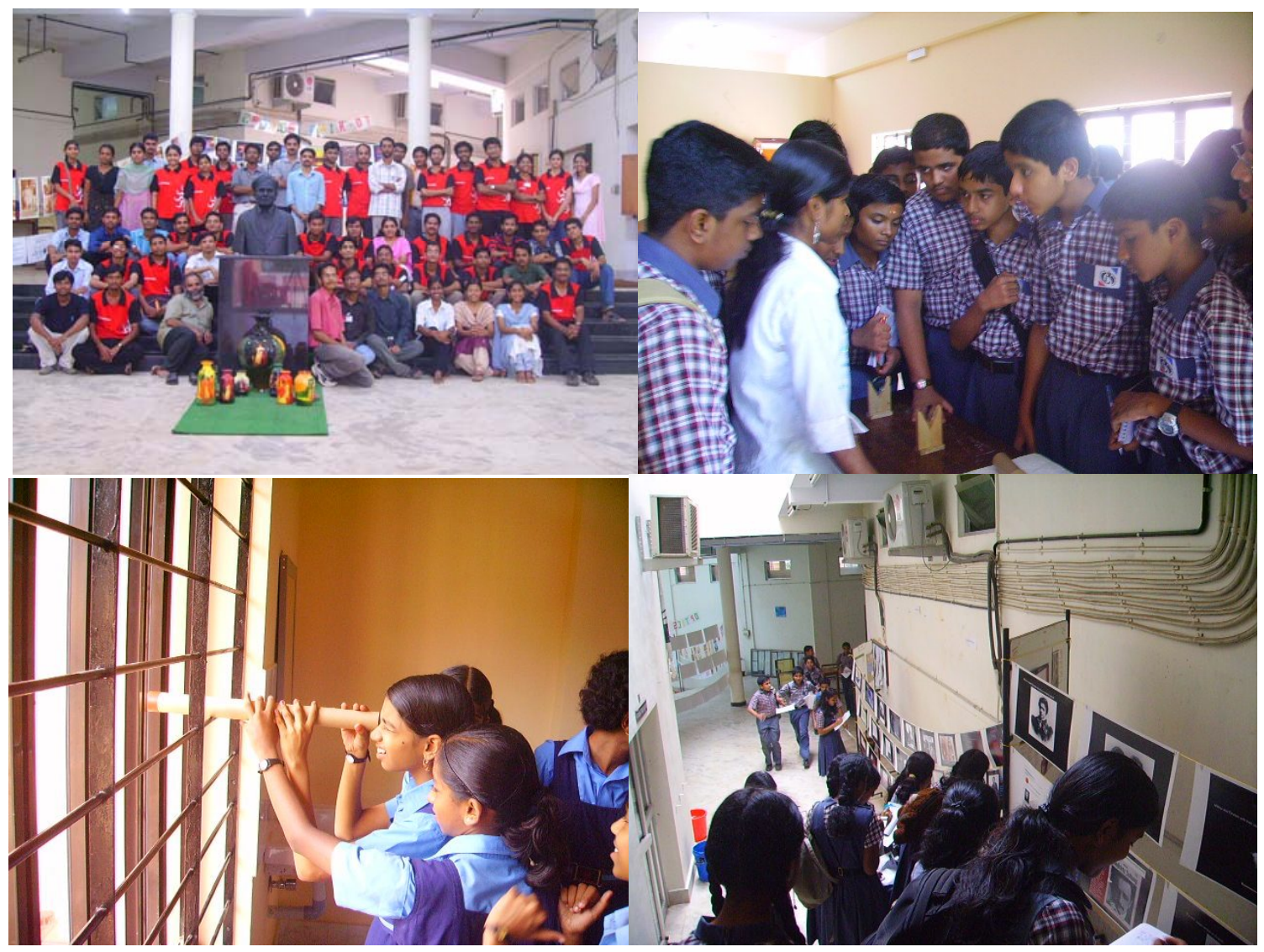

Figure 3: Photos from Optics fair 2007 


\section{Optics Fair}

Optics to school program proved to be a big success. But due to practical limitation of time, it was possible to conduct this event only for a limited number of schools in one academic year. In order to cater more number of students in a short span of time, idea of a massive outreach program named as "Optics Fair" was mooted. Achieving this idea demanded more organizational skills and more human efforts. The challenge was to setup all experiments under one roof for two days and cater maximum number of students possible in these two days.

This ambitious task was achieved in 2006 for the first time which was proved to be a big success followed by greater success in year 2007 and 2008. Every year this two day event catered more than 1400 students in three categories.

Other than the activity sessions, which ran similar to that in Optics to School, there were poster exhibitions. The poster exhibition on life and work of Prof. C. V. Raman was a special attraction of the event. Also there was screening of scientific documentaries. As a whole participants got a festive experience. They were living a day with optics. The event proved to be a great success for past three years with more positive responses each year.

\section{Conclusion}

A model for outreach activities was developed and successfully tested for four years. The content of the activity was carefully designed so that this program would act as a supplement to the regular curriculum for school students. But this content aimed to bridge the gap in the knowledge in optics due to the unrevised curriculum. The feedback obtained from students and teachers clearly shows that the approach adopted in designing the content of the program is appropriate. This is a generic model which could be adopted in countries where large numbers of students have to be addressed with limited resources in terms of time and trained manpower.

\section{REFERENCES}

1. Talisayon, V.M., Physics teaching in developing countries. Physics Education, 1984. 19(3): p. 105.

2. Gas, J.R., Science and science education in developing countries. International Review of Education, 1964. 10(1): p. 77-84.

3. Ashok, P.C., Massive Optics Outreach Event Held at ISP Chapter in SPIE Membership News. 2007.

4. M.Alarcon , E.A., Z.Ben Lakhdar ,I.Culaba ,V.Lakshminarayanan, J. Maquiligin, A. Mazzolini, J. Niemela, D. Sokolff, UNESCO: Active Learning in Physics for Developing Countries of Asia \& Africa, in World Conference on Physics and Sustainable Development. 2005: ICTP, Trieste. 